\title{
Multivariate Prediction Model of Strength and Acoustic Emission Energy considering Parameter Correlation of Coal or Rock
}

\author{
Shuncai Li, ${ }^{1,2}$ Daquan Li $\mathbb{D}^{3}{ }^{3}$ and Nong Zhang ${ }^{2,4}$ \\ ${ }^{1}$ JSNU-SPBPU Institute of Engineering, Jiangsu Normal University, Xuzhou, Jiangsu, China \\ ${ }^{2}$ State Key Laboratory of Coal Resources and Safe Mining, China University of Mining and Technology, Xuzhou, \\ Jiangsu 221116, China \\ ${ }^{3}$ School of Mechanical and Electrical Engineering, Jiangsu Normal University, Xuzhou, Jiangsu 221116, China \\ ${ }^{4}$ Open Laboratory for Large-Scale Scientific Instruments, Jiangsu Normal University, Xuzhou, Jiangsu 221116, China
}

Correspondence should be addressed to Daquan Li; 2020180517@jsnu.edu.cn

Received 9 March 2020; Accepted 13 May 2020; Published 29 May 2020

Academic Editor: Antonio Gloria

Copyright (c) 2020 Shuncai Li et al. This is an open access article distributed under the Creative Commons Attribution License, which permits unrestricted use, distribution, and reproduction in any medium, provided the original work is properly cited.

\begin{abstract}
Due to the heterogeneity of the internal structure and the different external loading conditions, the mechanical and acoustic emission (AE) characteristic parameters of coal and rock are discrete in the process of loading until failure, and many repeated and destructive tests need to be completed to obtain the performance parameters. It is of theoretical significance to explore the correlation of various parameters and to establish multiparameter regression models of coal rock strength and AE characteristics for predicting the strength and acoustic emission characteristic parameters of coal rock and reducing the repeated tests. For the coal sample from a coal seam of Longde Coal Mine in China, the mass density of coal samples and the acoustic velocity in the samples before loading are measured at first, and their respective coefficient of variation is analyzed. Then, the stress-strain curve and the time history curve of AE characteristic parameters are obtained by the uniaxial compression AE test of each coal sample according to the different loading rates. The influence of loading rate, mass density, and acoustic velocity on the mechanical and AE energy parameters of coal sample is analyzed by the section morphology of the coal sample after failure, the three-dimensional location map of AE, and the scanning micrograph of the electron microscope. Based on the least-square method, the multiple regression models of compressive strength, elastic modulus, and the maximum AE energy are established by mass density, acoustic velocity, and loading rate of coal samples. The results indicate that, for the coal samples from the same geological source, the obtained regression models can, respectively, predict the uniaxial compressive strength, elastic modulus, and the maximum $\mathrm{AE}$ energy according to the predesigned loading rate, the acoustic velocity, and mass density of coal samples measured before loading, without too many repeated loading failure tests.
\end{abstract}

\section{Introduction}

The deformation or fracture of coal and rock during loading may lead to some phenomena such as local stress concentration, rapid release of deformation energy in the form of stress wave, and accompanying with sound generation, and this phenomenon is called acoustic emission (AE), also known as stress wave emission. As a nondestructive testing technology, AE technology can monitor the internal deformation and rupture of coal rock in real time and continuously. The AE information can be used to analyze the strength and deformation properties of coal and rock. Khazaei et al. [1] proved that AE events were caused by fractures of intact rocks, so the change of $\mathrm{AE}$ in the loading process was largely related to fractures existing in rocks. Wang et al. [2] and Mlakar et al. [3] found that the change characteristics of AE signals were related to the failure of coal and rock, which could be used to monitor the progressive change of rock fracture development.

The acoustic emission test of uniaxial compression is the main means to obtain the compressive strength and acoustic emission characteristic parameters of coal and rock in the laboratory. However, due to the influence of various factors such as internal structure and external loading mode, the test results of coal and rock are discrete. 
There are many holes, cracks, and structural surfaces in coal and rock, so the fracture characteristics of coal and rock under the external load are very different. Wasantha et al. [4], Chen et al. [5], Liu et al. [6], and Yang et al. [7] studied the effect of rock bedding direction, joint inclination, and elliptical defect on the uniaxial compression mechanical behavior and energy emission of rock by experiments and numerical simulations. Liu et al. [8], Yan et al. [9], Hou et al. [10], and Lin et al. [11] studied the effects of bedding and microstructure on the Brazilian splitting and uniaxial compression properties of coal and rock by experiments. Tang et al. [12] and Song et al. [13] studied the influence of weak intercalation on the mechanical properties of coal. According to the experimental studies of Kong et al. [14] and Wang et al. [15], the uniaxial compressive strength and elastic modulus of coal and rock decrease with the increase of the initial number of fractures and its inclination.

The heterogeneity of coal samples is the main reason for the difference in failure characteristics of coal rock. Tang et al. [16] used the coefficient of heterogeneity to express the influence of internal heterogeneity of coal sample on its uniaxial compressive strength. Song et al. [17] and Wang et al. [18] studied the influence of rock heterogeneity on uniaxial compression failure and found that the distribution of $\mathrm{AE}$ events for uniform and nonuniform specimens is random in the early stage of loading. In the early stage of loading for nonuniform specimens, the AE energy peak is more likely to occur, and its strength is higher than that of uniform specimen.

In addition, the propagation velocity of acoustic wave in coal and rock is affected by various factors such as water saturation, porosity, microcracks, and pore distribution, so the wave velocity is an ideal parameter for expressing the anisotropy of coal and rock [19]. Some scholars have studied the relationship between uniaxial compressive strength and wave velocity in rock and established the relationship between compressive strength and wave velocity, diameter, and so forth [20-22]. Dehghan et al. [23] used regression and artificial neural network to predict uniaxial compressive strength and elastic modulus of rock with acoustic velocity as input parameters. Using the random forest method, Matin et al. [24] found that acoustic velocity is the most effective variable to predict uniaxial compressive strength and elastic modulus. Khandelwal and Xuzhou [25] established a simple mathematical model for predicting uniaxial compressive strength, Young's modulus, Poisson's ratio, and other parameters of coal and rock by using acoustic velocity. Jia et al. [26] found that the acoustic velocity and elastic modulus of coal rock under cyclic load significantly decreased when the rock was fractured.

Secondly, the strength and acoustic emission characteristics of rock samples are apt to be affected by external factors such as loading rate and loading path. By the uniaxial compression test of coal at different loading rates, Li et al. [27] found that there is a critical loading rate for the compressive strength of coal samples. Huang and Liu [28] conducted uniaxial compression tests for coal and rock at different loading rates and found that the higher the loading rate was, the more the peak stress and brittleness of coal and rock increased and the more the failure occurred. By experiments, Li et al. [29], Xue et al. [30], and other scholars found that, with the increase of loading rate, the peak strength of the coal sample first increased and then decreased. The research pointed out that the stress bias was the reason for the increase of the failure strength and the absorption energy density. Zhou et al. [31] found that, with the increase of loading rate, the crack growth rate and initial toughness increased. When the loading rate reached a certain value, the crack growth rate tended to be stable.

Considering the correlation between the parameters, some scholars propose to establish an appropriate model and can find some important unknown parameters by this model and some known parameters of coal and rock [32]. Qi et al. [33] established a nonlinear regression model of uniaxial compressive strength to the elastic modulus and natural density through experiments; by the uniaxial compression and tensile tests of 102 groups of coal samples, Zhang et al. [34] pointed out that there was a correlation among elastic modulus, uniaxial compressive strength, and tensile strength.

Due to the high discreteness of mechanical properties of coal and rock, it is generally necessary to conduct at least three repeated tests at the same loading condition to obtain the average value of mechanical parameters, which requires a large number of rock samples and a large amount of test work. In this paper, the influences of loading rate, acoustic velocity measured before loading, and mass density on mechanical and AE energy are considered. Taking the coal samples from Longde Coal Mine as an example, the regression model of coal acoustic emission energy, uniaxial compressive strength, and stiffness considering multifactor correlation was established, respectively, by compression tests under different loading rates. According to the established regression model, the AE energy, uniaxial compressive strength, and stiffness of coal and rock under the given loading rate can be predicted well without the destructive test based on the acoustic velocity value, mass density, and predesigned loading rate of coal and rock measured before the test.

\section{Test Samples and Equipment}

Coal samples are from Longde Coal Mine of China, and they are processed into standard cylindrical samples with nominal diameter $D$ of $50 \mathrm{~mm}$ and height $H$ of $100 \mathrm{~mm}$. The coal samples are marked as M1 M8. The coal sample size, density $\rho$, acoustic velocity $v_{s}$ in the coal sample, and the designed loading velocity $v_{c}$ are shown in Table 1 and Figure 1.

The equipment for the uniaxial compression and $\mathrm{AE}$ signal acquisition system with eight channels is as shown in Figure 2. The testing machine combines with the computer system, full-digital measurement-control system, and electrohydraulic servo system and can display various curves synchronously and in real time. Moreover, the microstructure of coals after loading was studied by using a JSM6510 scanning electron microscope (SEM). 
TABLE 1: Coal sample size and loading plan.

\begin{tabular}{|c|c|c|c|c|c|}
\hline Sample number & $D(\mathrm{~mm})$ & $H(\mathrm{~mm})$ & $\rho\left(10^{3} \mathrm{~kg} / \mathrm{m}^{3}\right)$ & $v_{s}(\mathrm{~m} / \mathrm{s})$ & $v_{c}(\mathrm{~mm} / \mathrm{min})$ \\
\hline M1 & 49.30 & 101.10 & 1.27 & 935 & 0.012 \\
\hline M2 & 49.32 & 101.00 & 1.27 & 914 & 0.016 \\
\hline M3 & 49.42 & 100.60 & 1.23 & 321 & 0.018 \\
\hline M4 & 49.36 & 99.00 & 1.27 & 914 & 0.020 \\
\hline M5 & 49.32 & 101.46 & 1.22 & 1693 & 0.022 \\
\hline M6 & 49.30 & 101.00 & 1.37 & 1968 & 0.026 \\
\hline M7 & 49.42 & 100.60 & 1.27 & 630 & 0.028 \\
\hline M8 & 49.32 & 101.00 & 1.40 & 999 & 0.032 \\
\hline
\end{tabular}

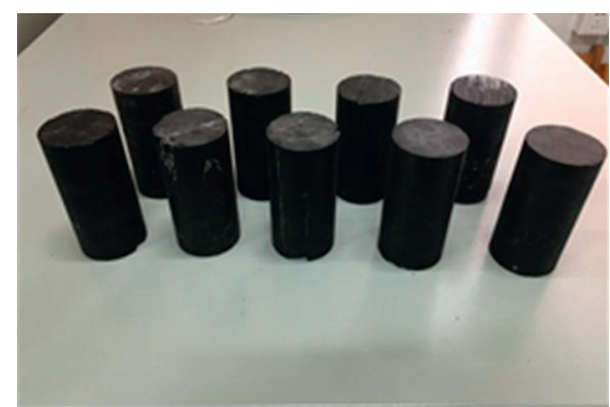

Figure 1: Coal samples before the test.

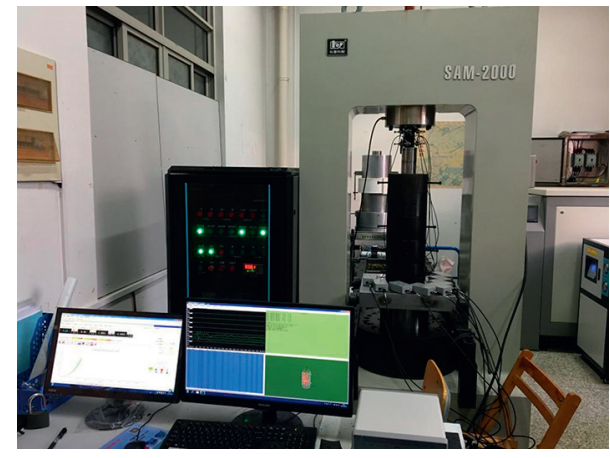

FIgURE 2: Test equipment.

\section{Research Scheme and Test Procedures}

Firstly, we conducted the breaking lead tests to obtain acoustic velocity $v_{s}$ in coal samples; secondly, we finished the $\mathrm{AE}$ experiments during uniaxial compression by the predesigned loading velocity $v_{c}$ to obtain the characteristic parameters of mechanics and $\mathrm{AE}$ of the coal samples. According to the test data, the curve of stress and AE energy changing with time was drawn, and then the AE and mechanical characteristics of coal samples were analyzed. Multiple regression models of acoustic emission energy, strength, and stiffness were established. The research scheme is as shown in Figure 3.

Main procedures of the experiments are as follows:

(1) Measure the coal samples' size and mass, and then calculate their mass density.

(2) Determine the acoustic velocity value $v_{s}$ in coal samples by breaking lead test with $\mathrm{AE}$ instrument as shown in Figure 4 . The measured acoustic velocity values in each specimen are shown in Table 1.

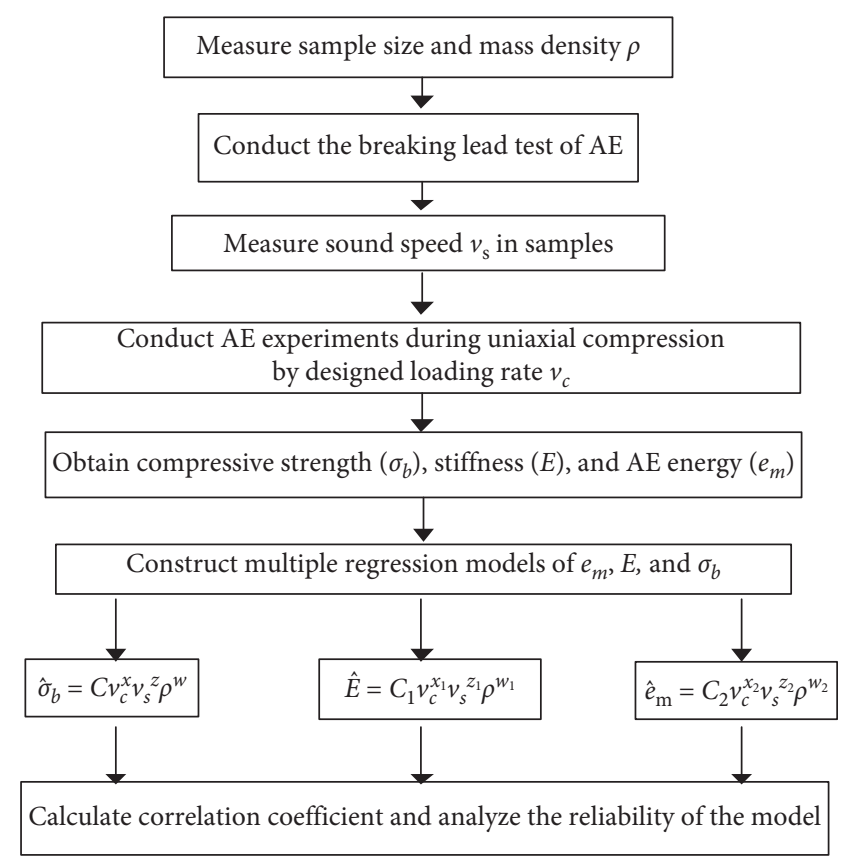

Figure 3: Study scheme.

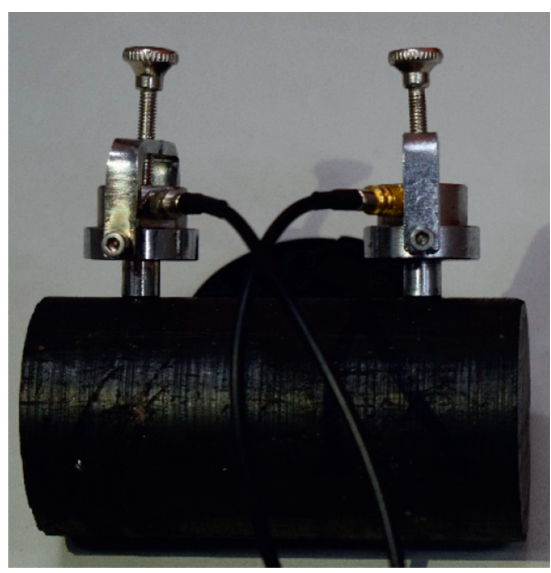

Figure 4: Acoustic velocity measurement.

(3) Conduct a uniaxial compression AE test on the selected samples according to the loading rate set in Table 1. The AE instrument used in the laboratory is the Soft Island DS2-B series, which adopts a USB2.0 interface form, which can perform up to eight channels of information acquisition and positioning. 
The eight sensors are clockwise, the top sensors are numbered $1,2,3$, and 4 , and the bottom sensors are $5,6,7$, and 8. Each sensor is $20 \mathrm{~mm}$ from the end face of the sample. The position of the installed sample AE sensor is shown in Figure 5. The sensor and the converter are bonded with the relevant coupling agent, and the sensor and the sample are bonded with ordinary glue. Collect the characteristic parameters of coal samples such as the axial force, axial displacement, and AE energy. These data are used to draw the stress-strain curve to obtain its elastic modulus $E$ and its compressive strength $\sigma_{b}$.

(4) Use scanning electron microscopy to observe the microstructure of the coal sample and the threedimensional map of acoustic emission to analyze the deformation and failure characteristics of the coallike structure under external force.

(5) Establish a multivariate regression model to predict AE energy, uniaxial compressive strength, and stiffness of coal samples based on loading rate, acoustic velocity, and density of coal samples.

\section{Discrete Analysis of the Mass Density and Acoustic Velocity of Coal Samples}

According to Table 1, the curves of mass density $\rho$ and acoustic velocity $v_{s}$ of coal samples are as shown in Figure 6. Four of the eight coal samples have a mass density of $1270 \mathrm{~kg} / \mathrm{m}^{3}$, and the density of the other four coal samples was different. The acoustic velocity value of coal sample is discrete, and its value changes from $321 \mathrm{~m} / \mathrm{s}$ to $1968 \mathrm{~m} / \mathrm{s}$. According to Table 1, we can, respectively, calculate the average value $\bar{X}$ of coal sample density and acoustic velocity and then calculate the sample standard deviation $S$ and its coefficient of variation (simplified as $\mathrm{CV}$, $\mathrm{CV}=(S / \bar{X}) \times 100 \%)$ as shown in Table 2 . The variation coefficient of the density of the coal sample is $4.67 \%$, while the variation coefficient of acoustic velocity in the coal sample is $49.57 \%$. Since the acoustic velocity value is a comprehensive reaction of the internal defects and physical properties of the coal samples, we can see that the mechanical properties of the coal samples from the same stratum of Longde Coal Mine have a large dispersion.

\section{Analysis of AE Characteristics of Coal Samples}

5.1. Time History Curve of Axial Stress and AE Energy of Coal Sample. Collect the mechanics and AE characteristics of each coal sample and then we obtain the curves of the stress and AE energy changing with time by MATLAB software, as shown in Figure 7.

According to Figure 7, the time curves of stress and AE energy can be roughly divided into three stages.

5.1.1. Initial Loading Stage. At this stage, the original open structural surface or microcracks in the coal sample gradually closed, and the surface of the coal sample was

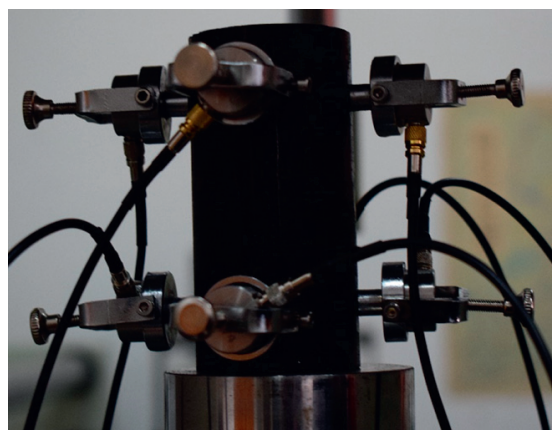

FIGURE 5: Location distribution of acoustic emission sensor.

deformed, forming microcracks and generating AE signals. In the early stage of loading, the stress of the coal sample is small and the deformation is not significant, so the emitted $\mathrm{AE}$ energy is less. However, the AE energy value of the samples M5 and M8 is higher in the early stage than that in the other stages. Maybe it is because there are large defects in the coal sample, and the coal sample forms a large crack when it is loaded, resulting in a higher AE energy release in the coal sample.

5.1.2. Linear Elastic Stage. As the loading progresses, the coal sample is in an elastic deformation stage. At this time, the microrupture of the coal sample develops steadily, so the AE energy is more uniform at this stage.

5.1.3. Plastic Deformation Stage. In the loading process, a large amount of energy is accumulated in the coal sample, which accelerates the deformation process. The internal cracks and fractures in the coal sample increase at a faster rate and eventually form macroscopic failure. At this point, due to the destruction of the coal sample, the coal sample released a large amount of energy, and the peak of AE energy occurred. For example, when the stress of M1 and M2 samples reached a peak, AE energy also reached a peak.

Because there are many pores and fractures in coal, in the early stage of sample loading, the pores are compacted and the stress changes little, but the AE energy has a distinct change. Therefore, in Figure 7, in the three samples of $a, c$, and $e$, the stress changes in the early stage are small, and the stress increases sharply in the middle stage, but the $\mathrm{AE}$ energy still changes in the early stage.

In Figure 7, both $f$ and $g$ have the maximum AE energy value before the stress peak. This is because part of the coal sample has been destroyed before the peak load is reached, and the damaged part is sputtered, so the maximum $\mathrm{AE}$ energy value is reached before the peak load is reached.

5.2. Effect of Loading Rate and Acoustic Velocity on Acoustic Emission Characteristics of Coal Samples. The acoustic emission parameters obtained by the above experiments are as follows: average ringing count $n_{a}$, average AE energy $e_{a}$, average collisions number $h_{a}$, maximum ringing count $n_{m}$, maximum energy $e_{m}$, maximum collisions number $h_{m}$, and 


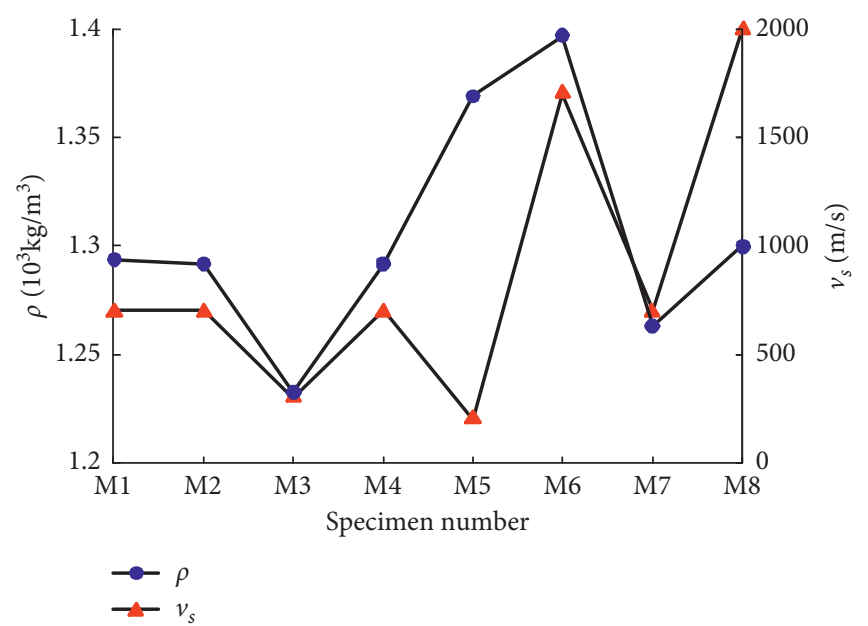

Figure 6: Distribution curve of mass density and acoustic velocity in coal samples.

TABLE 2: Discrete statistics of mass density and acoustic velocity in coal samples.

\begin{tabular}{lccc}
\hline Items & Average value $\bar{X}$ & Standard deviation $S$ & Coefficient of variation CV (\%) \\
\hline$\rho\left(10^{3} \mathrm{~kg} / \mathrm{m}^{3}\right)$ & 1.29 & 0.06 & 4.67 \\
$v_{s}(\mathrm{~m} / \mathrm{s})$ & 1023.11 & 507.07 & 49.56 \\
\hline
\end{tabular}

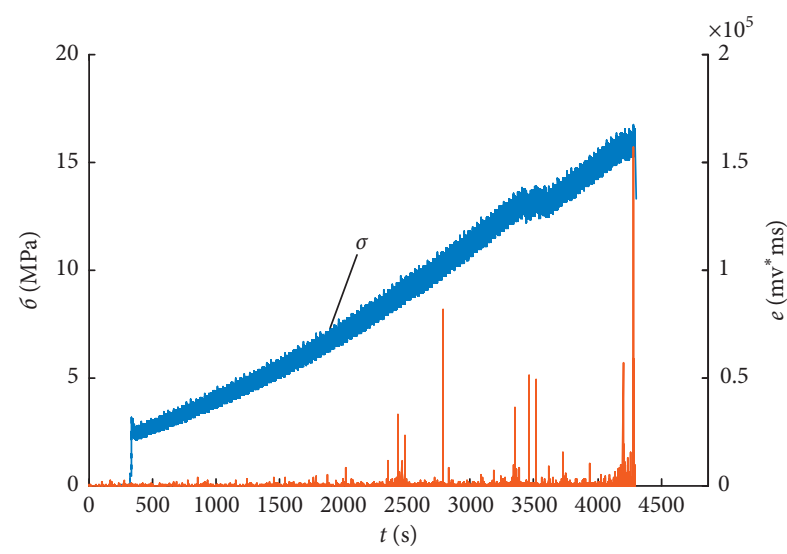

(a)

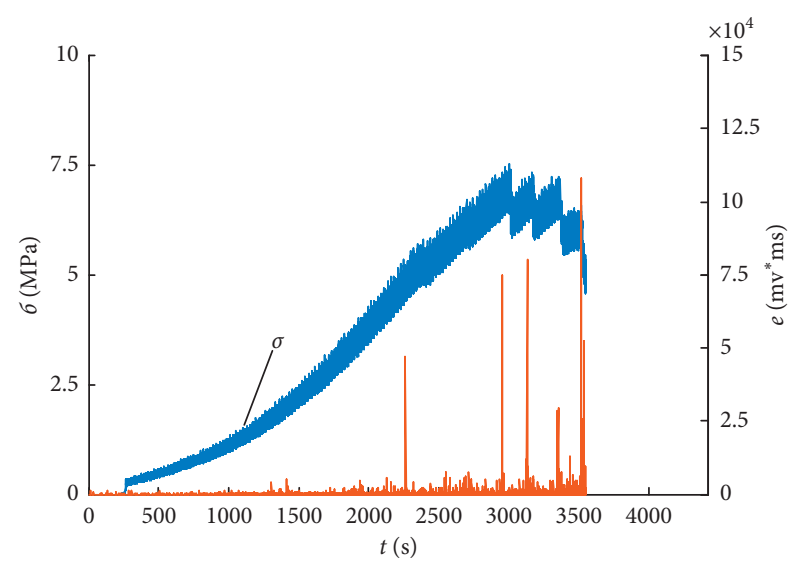

(c)

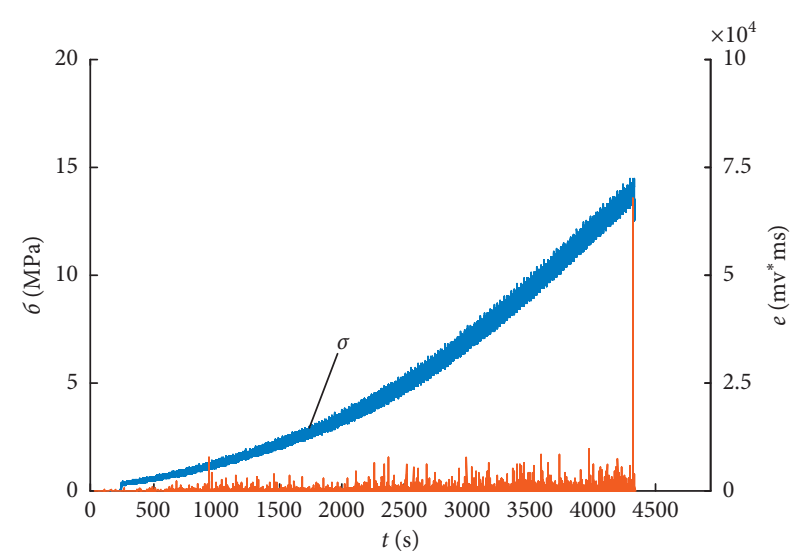

(b)

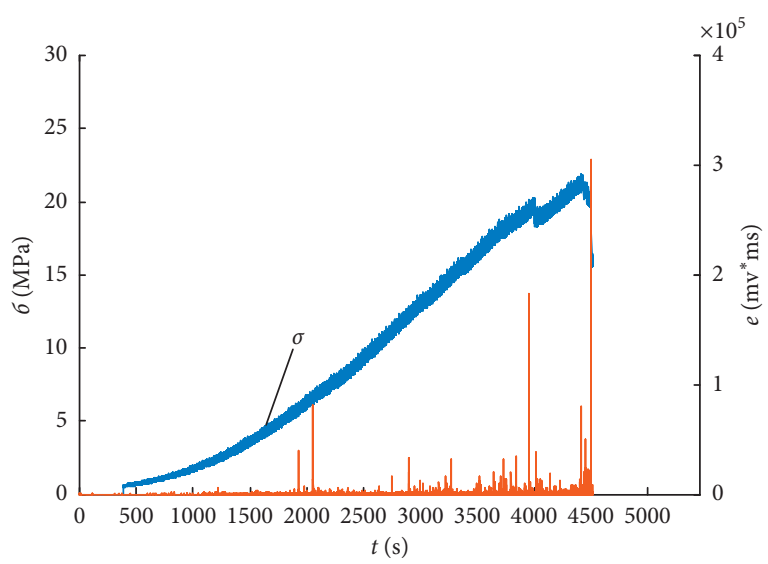

(d)

Figure 7: Continued. 


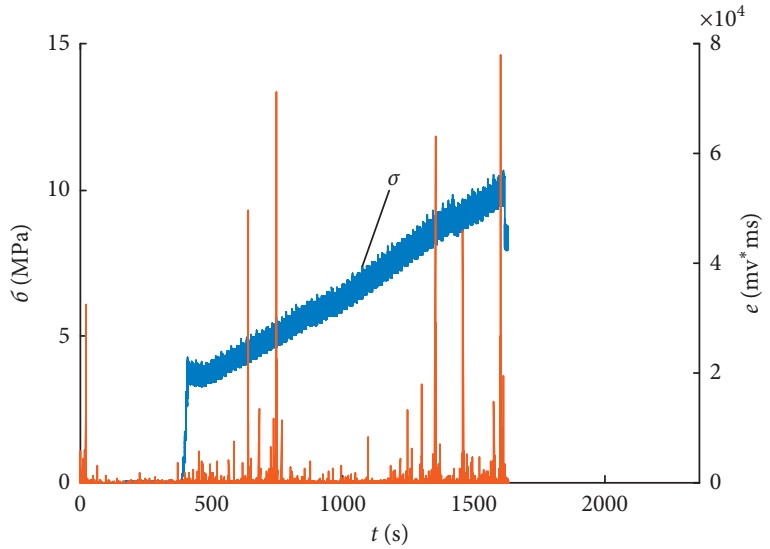

(e)

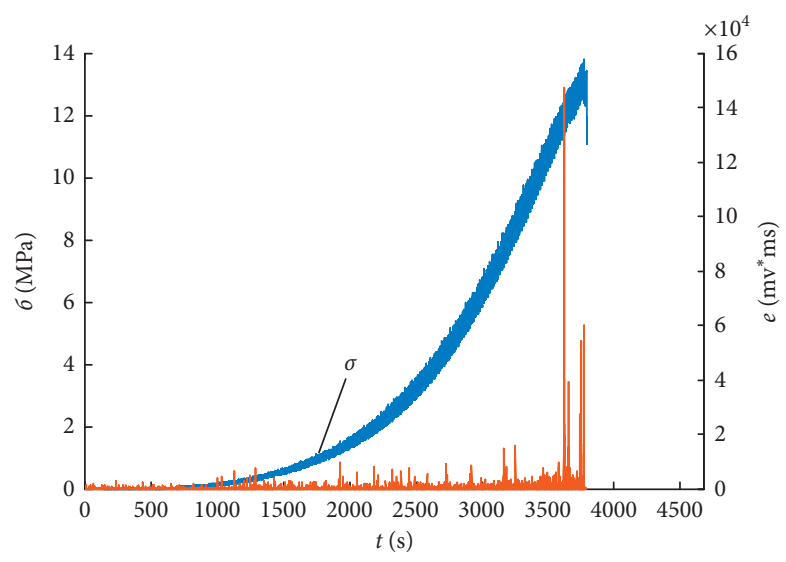

(g)

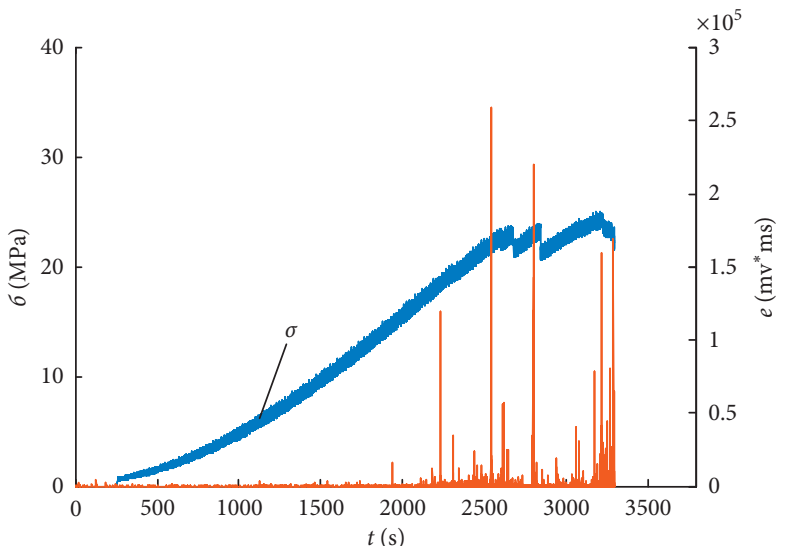

(f)

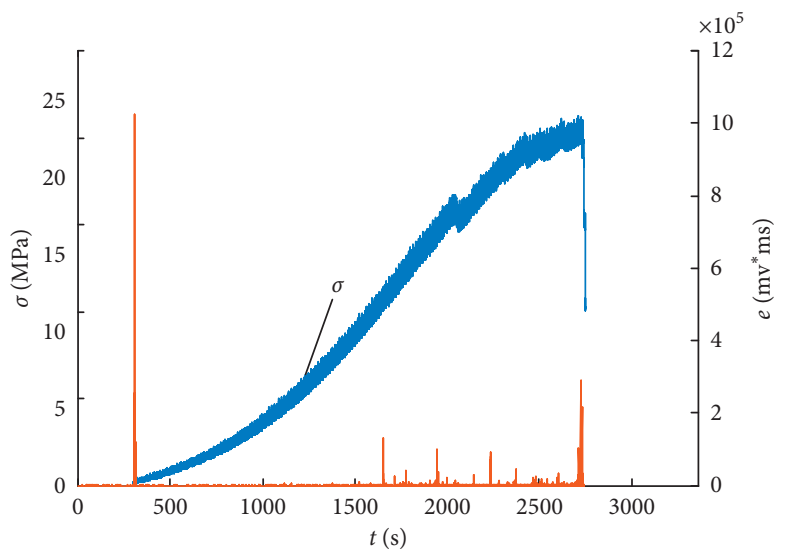

(h)

Figure 7: Curves of stress and AE energy changing with time. (a) M1 ( $v=0.012 \mathrm{~mm} / \mathrm{s})$. (b) M2 $(v=0.016 \mathrm{~mm} / \mathrm{s})$. (c) M3 ( $v=0.018 \mathrm{~mm} / \mathrm{s})$. (d) M4 $(v=0.020 \mathrm{~mm} / \mathrm{s})$. (e) M5 $(v=0.022 \mathrm{~mm} / \mathrm{s})$. (f) M6 ( $v=0.026 \mathrm{~mm} / \mathrm{s})$. (g) M7 $(v=0.028 \mathrm{~mm} / \mathrm{s})$. (h) M8 $(v=0.032 \mathrm{~mm} / \mathrm{s})$.

so forth. The AE parameters for each coal sample are as shown in Table 3.

According to Table 3, we can see that, with the increase of the loading rate, the maximum energy $e_{m}$ in the coal sample is up to $1023902 \mathrm{mv}^{*} \mathrm{~ms}$ and the lowest is $67910 \mathrm{mv}^{*} \mathrm{~ms}$. The maximum value of the average ringing count is 37 , and the minimum value is 16 . The average maximum energy is $222 \mathrm{mv}^{*} \mathrm{~ms}$, and the minimum energy is $113 \mathrm{mv}^{*} \mathrm{~ms}$. The maximum value of the average collisions number is 11014 and the minimum is 3426 .

According to Tables 1 and 3, the comparison curves of maximum AE energy $e_{m}$ and acoustic velocity $v_{s}$ for coal samples (each sample has a different loading rate) were obtained as shown in Figure 8.

According to Table 3, it can be seen that changing characteristics of the AE ring number of each coal sample are consistent with those of the AE energy; thus, without loss of generality, the maximum AE energy of coal samples is selected as the representative of $\mathrm{AE}$ characteristics of coal samples. As can be seen from Figure 7, the peak change of AE energy was affected comprehensively by the loading rate and acoustic velocity, which could not be analyzed solely from the perspective of acoustic velocity or loading rate.
However, when the loading rate reached a certain critical value, there was a huge change in the peak value of $\mathrm{AE}$ energy. The acoustic velocity value of M8 coal sample (its load rate is $0.032 \mathrm{~mm} / \mathrm{min}$ ) is not the largest among all the samples, but its AE energy is far greater than that of the other coal samples. This indicates that, in the uniaxial compression test of coal samples, when the loading rate is too large, the effect of the external loading rate on the AE energy of coal samples is greater than that of the acoustic velocity.

\section{Analysis of Mechanical Properties of Coal Samples}

6.1. Stress-Strain Curve of Coal Samples. According to the test data, the stress-strain $\varepsilon$ curves of coal samples corresponding to different loading rates are as shown in Figure 9.

By observing the above stress-strain curves, it can be found that the deformation process of coal samples in the uniaxial compression test can be roughly divided into the following four stages: pore-fracture compaction stage, elastic deformation to the stable development stage of microelastic fractures, nonstable fracture development stage, and postfracture stage. 
TABLE 3: Acoustic emission parameters for each sample.

\begin{tabular}{|c|c|c|c|c|c|c|}
\hline \multirow{2}{*}{ Sample number } & \multicolumn{2}{|c|}{ Mean value of parameters } & \multicolumn{4}{|c|}{ Maximum value of parameters } \\
\hline & $n_{a}$ (times) & $e_{a}\left(\mathrm{mv}^{*} \mathrm{~ms}\right)$ & $h_{a}$ (times) & $n_{m}$ (times) & $e_{m}\left(\mathrm{mv}^{*} \mathrm{~ms}\right)$ & $h_{m}$ (times) \\
\hline M1 & 20 & 222 & 5040 & 7311 & 157021 & 162058 \\
\hline M2 & 16 & 127 & 5527 & 14036 & 67910 & 13890 \\
\hline M3 & 16 & 113 & 9733 & 16193 & 108119 & 22657 \\
\hline M4 & 22 & 217 & 9855 & 20135 & 304986 & 23545 \\
\hline M5 & 21 & 169 & 3426 & 9875 & 78021 & 10071 \\
\hline M6 & 24 & 202 & 9448 & 22526 & 259180 & 27037 \\
\hline M7 & 18 & 148 & 7390 & 24282 & 147724 & 18428 \\
\hline M8 & 37 & 182 & 11014 & 1167324 & 1023902 & 27107 \\
\hline
\end{tabular}

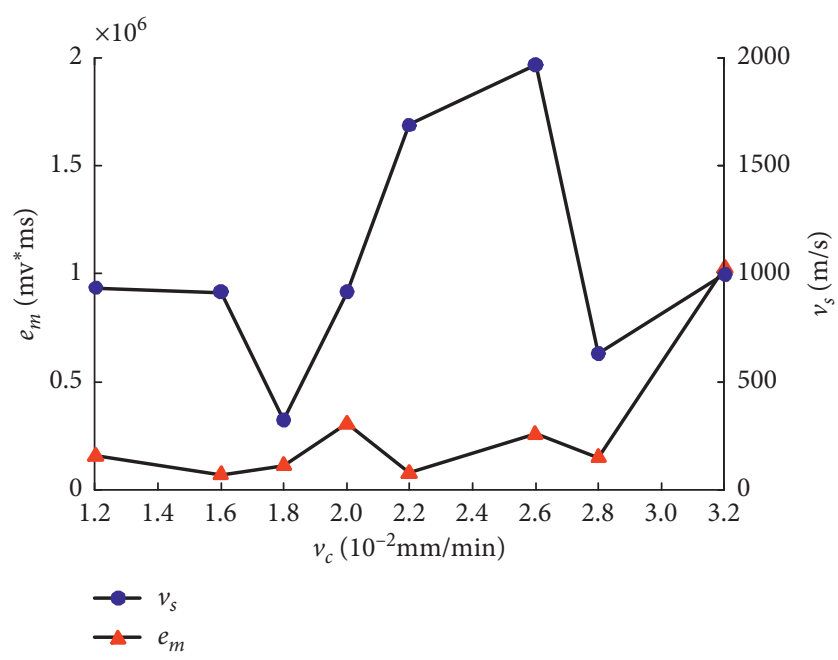

Figure 8: Curve of $e_{m}$ and $v_{s}$ for coal samples with different loading rates $v_{c}$.

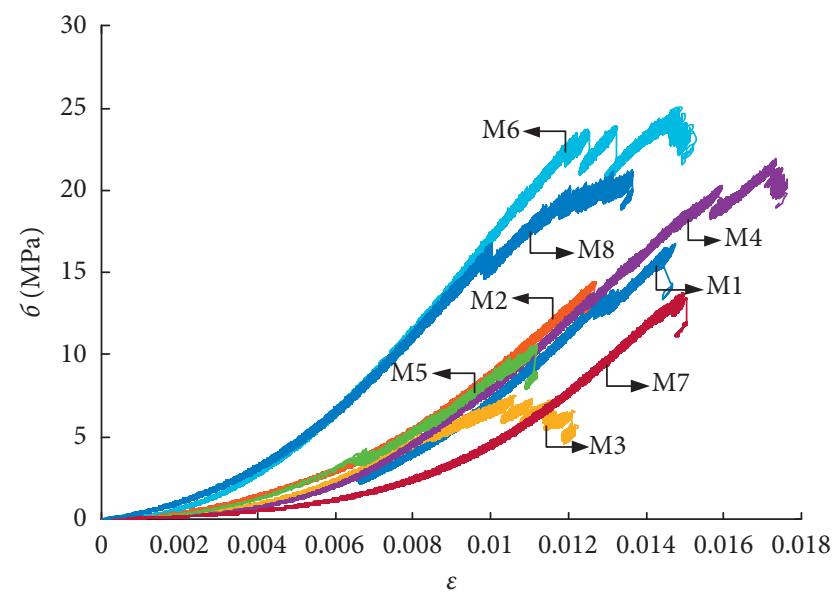

Figure 9: Stress-strain curve of coal samples.

The main parameters of the mechanical properties of coal samples obtained based on the test are as follows: peak load $F_{b}$, compressive strength $\sigma_{b}$, elasticity modulus $E$, and compression rate $\phi$.

6.2. Effects of Loading Rate and Acoustic Velocity on Mechanical Properties of Coal Samples. According to Table 4, uniaxial compressive strength and compression rate curves
TABle 4: Mechanical properties' parameters of coal samples.

\begin{tabular}{lcccc}
\hline Specimen number & $F_{b}(\mathrm{kN})$ & $\sigma_{b}(\mathrm{MPa})$ & $\phi(\%)$ & $E(\mathrm{GPa})$ \\
\hline M1 & 31.95 & 16.74 & 1.49 & 1.80 \\
M2 & 27.65 & 14.47 & 1.28 & 1.02 \\
M3 & 14.47 & 7.54 & 1.23 & 0.78 \\
M4 & 41.90 & 21.90 & 1.75 & 1.69 \\
M5 & 20.36 & 10.66 & 1.13 & 1.59 \\
M6 & 47.87 & 25.08 & 1.54 & 2.74 \\
M7 & 26.46 & 13.80 & 1.51 & 1.45 \\
M8 & 40.61 & 21.26 & 1.39 & 2.34 \\
\hline
\end{tabular}

of each coal sample under the corresponding loading rate can be obtained as Figure 10. It can be seen that the compressive strength $\sigma_{b}$ and compression rate $\phi$ of coal samples do not increase or decrease monotonously with the loading rate. In general, the compressive strength and compression rate show a positive correlation, the compression rate of samples with high compressive strength is also high, and the compressive strength $\sigma_{b}$ and compression rate $\phi$ are relatively large at the medium loading rate.

Figure 10 shows the comparison curves of the acoustic velocity $v_{s}$, compressive strength $\sigma_{b}$, the elastic modulus $E$, and compression ratio $\phi$. According to Figure 10, generally speaking, the samples with high acoustic velocity also have 


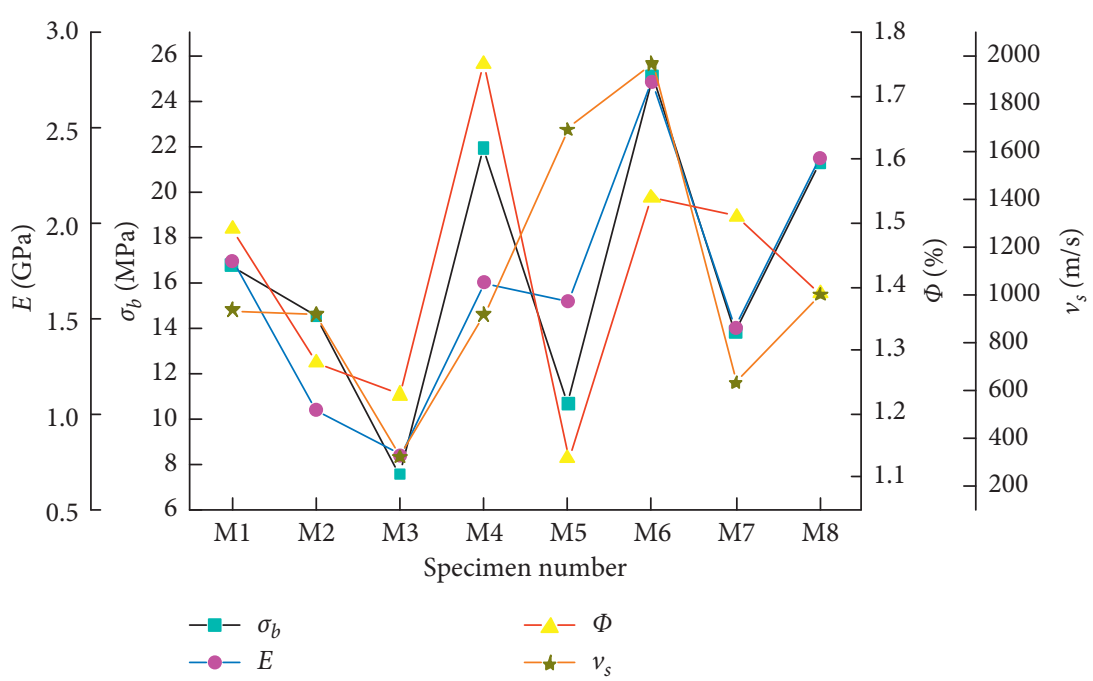

Figure 10: Comparison curve of $\sigma_{b}, E, \phi$, and $v_{s}$ of coal samples.

high compressive strength and elastic modulus (except for M5). The M6 sample has the highest acoustic velocity, compressive strength, and elastic modulus. The acoustic velocity of M3 is the lowest and so are its compressive strength and elastic modulus. The results show that there is a strong positive correlation between strength, stiffness, and acoustic velocity.

In Figure 10, the changes in sound velocity and strength, stiffness, and compression rate of the M5 sample are inconsistent, indicating that the sound velocity is not an only parameter that determines the mechanical properties of the coal sample. Other factors also have important effects on the mechanical properties of the coal sample.

\section{AE 3D Localization Map and Scanning Electron Microscope (SEM) Diagram of the Coal Samples}

The fractured coal samples and their 3D AE localization map are shown in Figure 11.

According to Figure 11, we can see the following:

(1) For the M1 and M3 samples, the failure form is the single inclined plane shear failure. During the loading process, one side of the specimen ruptured and caved first.

(2) The M2 sample split from the middle, which has cracks on the surface, but the crack does not get transfixed in the axial direction.

(3) The coal samples M4 and M5 are X-shaped conjugate slope shear failure. The slope angle is approximately 45 degrees.

(4) The M7 coal sample was split, and, after fracture, it formed a transfixion fracture parallel to the loading direction.

(5) Specimen M8 was fractured seriously, with failure surfaces at both ends and sides of the specimen.
The loading rate of the eight coal samples was designed to gradually increase. According to the fracture diagram of the coal samples after the test, the damage degree of the M8 coal sample with the highest loading rate was significant. The M3 coal sample is also seriously damaged; also we note that its acoustic velocity is the lowest, so the homogeneity is the worst and the damage is the most serious.

It can be seen from the acoustic source location diagram of the coal sample that a large number of energy points are accumulated near the fracture zone of the coal sample, which indicates that the fracture process of the coal sample during compression is actually a process of energy accumulation. Besides, the acoustic source locational map of coal samples shows that the acoustic source locus is in good agreement with the fracture surface of coal samples. For example, in the coal sample M2, the coal sample did not significantly damage from the macro aspect, and, in its $\mathrm{AE} 3 \mathrm{D}$ positioning, the location of the sound source is more dispersed and evenly distributed throughout the coal sample. Therefore, AE technology can obtain internal defects of materials, timely obtain precursor information of material damage, and provide the scientific basis for monitoring geological hazards.

Figure 12 is a micrograph of the coal sample debris after loading. The coal sample has obvious heterogeneity, and there are many holes, cracks, and other impurities inside, so when the coal sample is damaged under the action of external load, this damage is essentially the process of the generation, expansion, and penetration of the internal defects of the coal sample. The microscopic analysis of the broken coal pieces can better analyze the stability of coal structure when coal is subjected to external action.

Combined with the macroscopic failure diagram of the coal sample, it can be seen that most of the coal samples were obviously damaged such as specimens M2 M8. However, specimen M6 is less damaged after fracture. There are few holes and few cracks in specimen M6 compared with other coal samples. We can conclude that specimen M6 has higher homogeneity and larger compressive strength and stiffness, so it has a strong resistance to failure. While the loading rate 


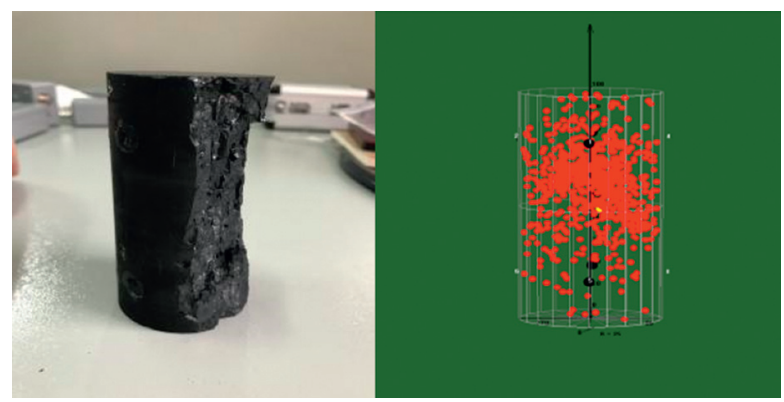

(a)

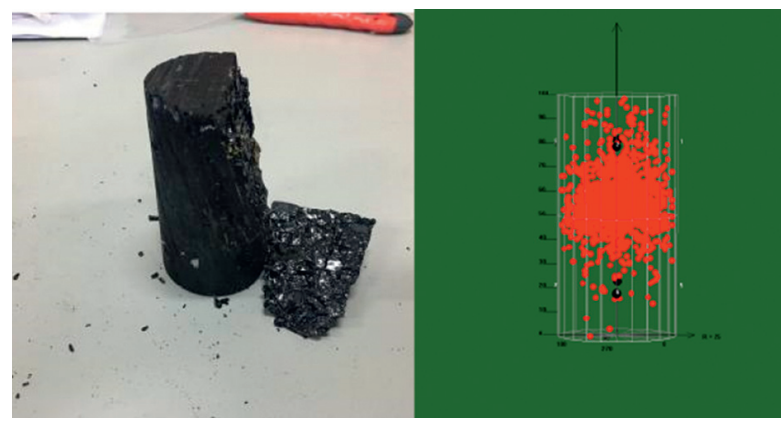

(c)

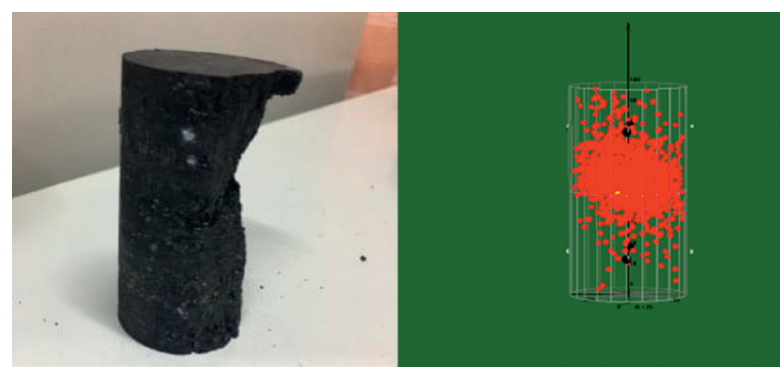

(e)

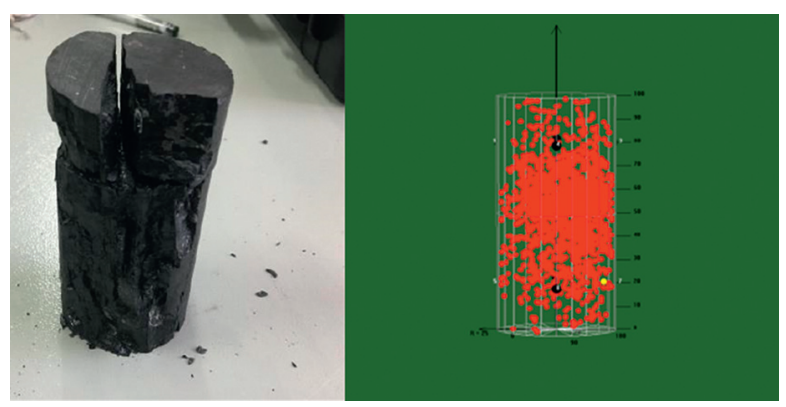

(g)

FIGURE 11: Coal samples after fracture and 3D AE localization map. of the M3 sample is small, it has the minimum acoustic velocity and small density before loading. In addition, according to the micrograph of the M3 sample where there are many cracks, the broken edges and corners are obvious. Compared with other coal samples, the fracture angle is large, so the failure degree is also significant. In the macrodestructed coal samples, the form of macrodestruction is different, and the microperformance is also different. For example, in the case of macrofailure, in the split and sheared coal samples, the split-shaped coal

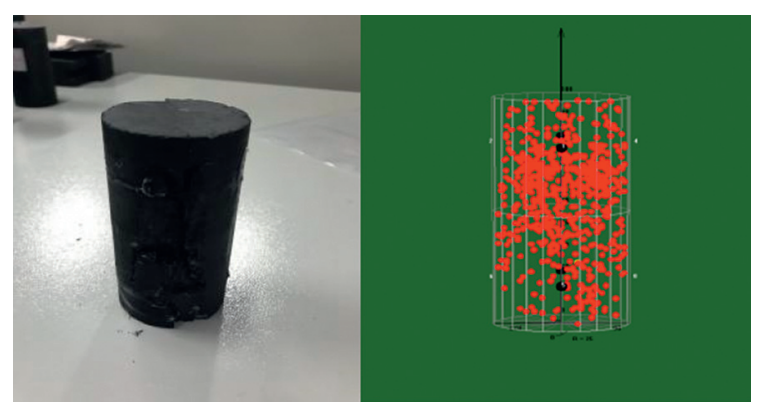

(b)

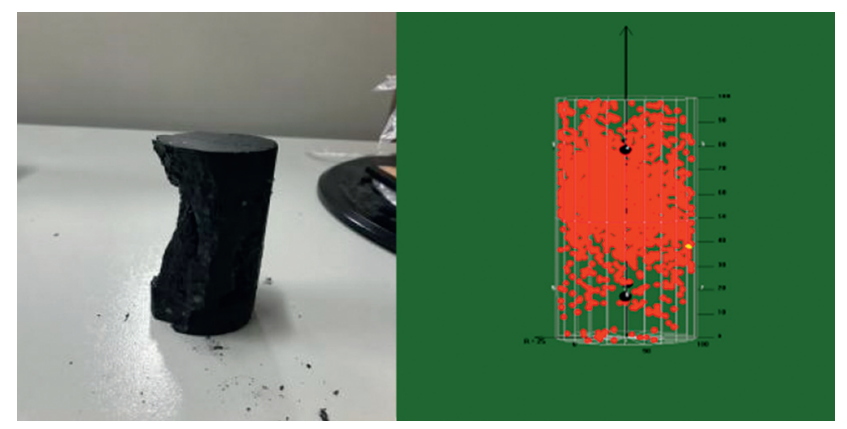

(d)

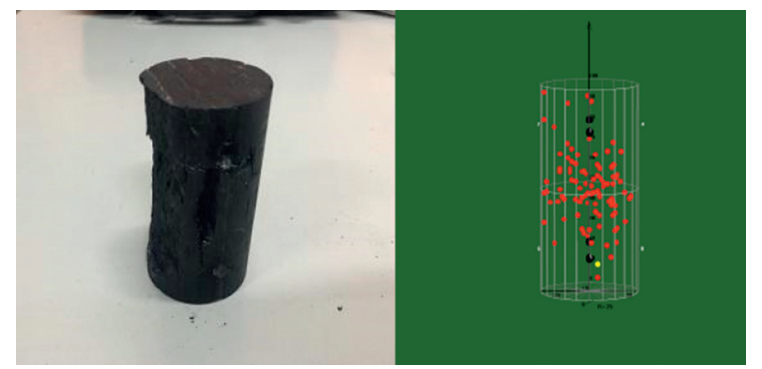

(f)

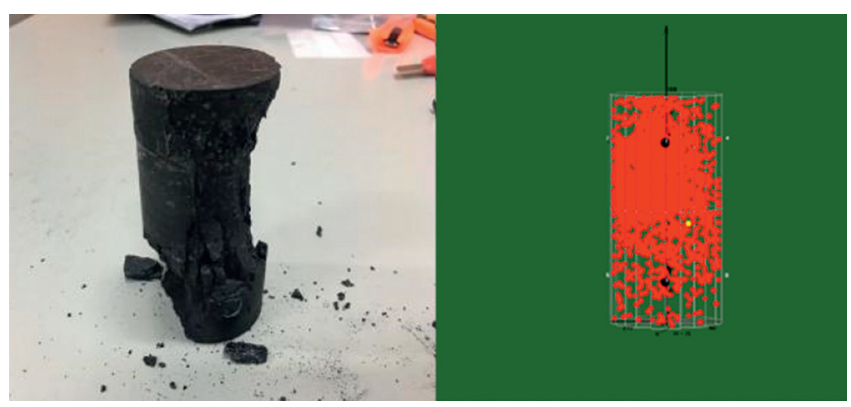

(h)
. (a) M1. (b) M2. (c) M3. (d) M4. (e) M5. (f) M6. (g) M7. (h) M8.

samples are smoother, and the sheared coal samples have more surface cracks.

\section{Multiple Regression Models of AE Energy, Strength, and Stiffness of Coal Samples}

According to the test, the loading rate, the mass density of the coal sample, and the acoustic velocity in the coal sample all influence the mechanics and AE characteristics of the coal sample. Based on the data given in Tables 1 and 3, the 


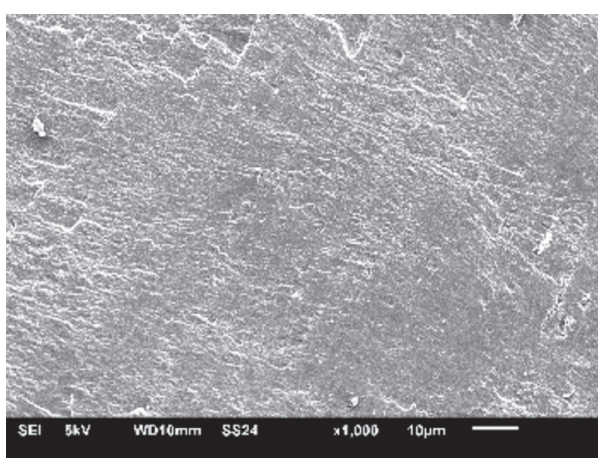

(a)

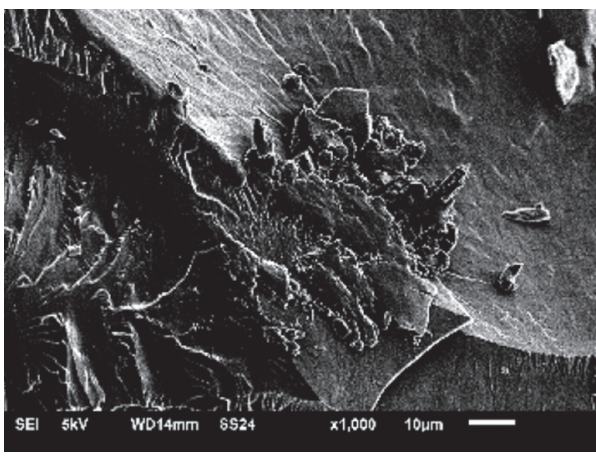

(c)

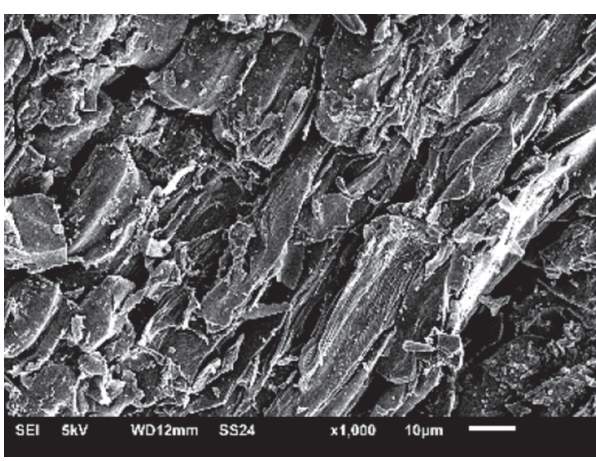

(e)

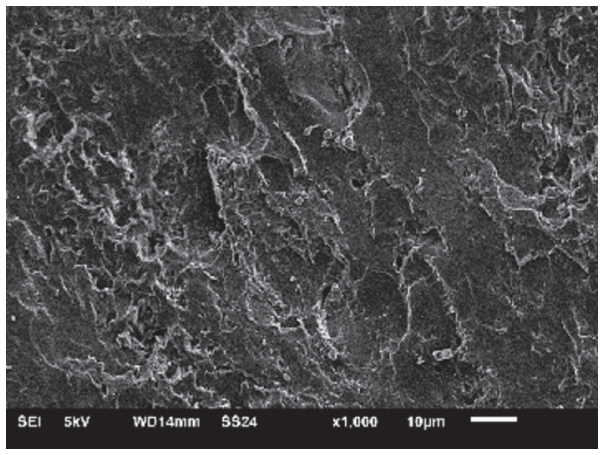

(g)

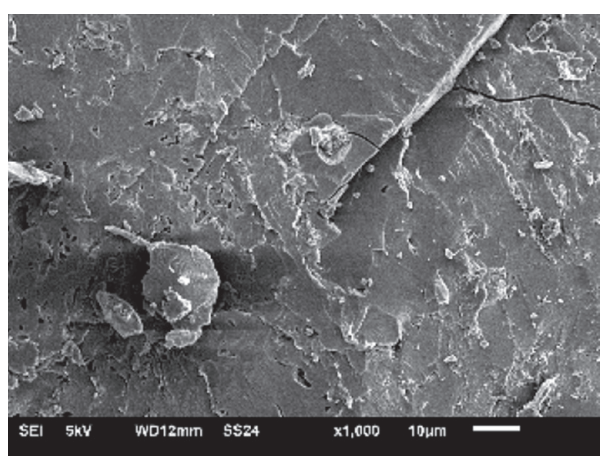

(b)

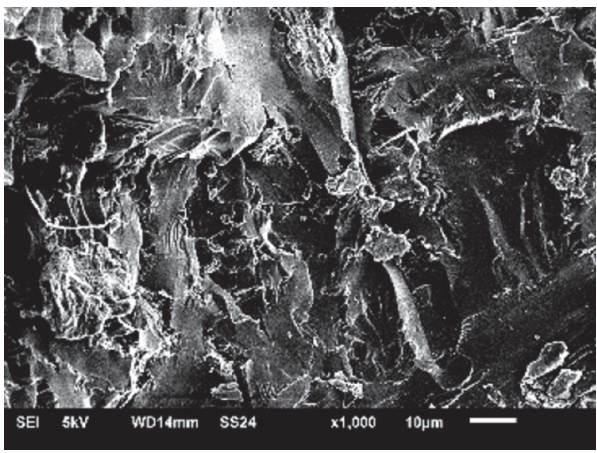

(d)

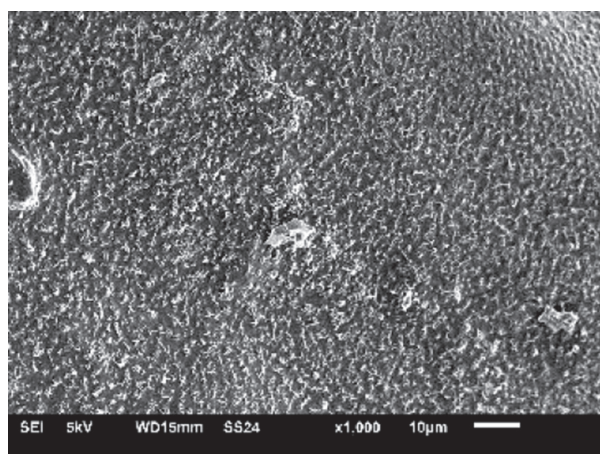

(f)

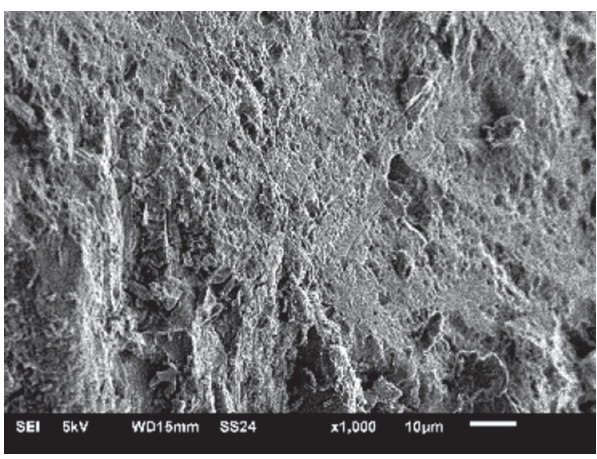

(h)

Figure 12: Microstructure of coal sample debris after loading. (a) M1. (b) M2. (c) M3. (d) M4. (e) M5. (f) M6. (g) M7. (h) M8.

regression model of maximum $\mathrm{AE}$ energy $e_{m}$, compressive strength $\sigma_{b}$, and elastic modulus $E$ can be, respectively, established with coal loading rate, acoustic velocity, and sample density as independent variables by the least-square method. Taking the regression model establishment of $\mathrm{AE}$ energy $e_{m}$ as an example, we set up

$$
\widehat{e}_{m}=C v_{c}^{x} v_{s}^{z} \rho^{w} \text {. }
$$


In equation (1), $v_{c}$ is the loading rate, $v_{s}$ is the acoustic velocity in preloaded coal sample, $\rho$ is the mass density of the coal sample, and $\widehat{e}_{m}$ is the prediction value of the maximum AE energy $e_{m}$ of the coal sample. $C, x, z$, and $w$ are pending parameters.

By taking logarithms on both sides of equation (1), we can obtain the following equation:

$$
\ln \widehat{e}_{m}=\ln C+x \ln v_{c}+z \ln v_{s}+w \ln \rho .
$$

Record the measured value of the maximum AE energy values in each test as $e_{m_{i}}(i=1,2, \ldots, 8)$; the logarithmic difference between the fitted AE energy value $\widehat{e}_{m}$ and the measured value $e_{m}$ is

$$
\ln C+x \ln v_{c_{i}}+z \ln v_{s_{i}}+w \ln \rho_{i}-\ln e_{m_{i}} .
$$

According to equation (3), the sum of the squares of the errors is as follows:

$$
\sum_{i=1}^{8}\left(\ln C+x \ln v_{c_{i}}+z \ln v_{s_{i}}+w \ln \rho_{i}-\ln e_{m_{i}}\right)^{2} .
$$

Let $\Pi=\sum_{i=1}^{8}$ $\left(\ln C+x \ln v_{c_{i}}+z \ln v_{s_{i}}+w \ln \rho_{i}-\ln e_{m_{i}}\right)^{2}, \ln C=\eta$.

According to the least-square method, let $(\partial \Pi / \partial x)=0,(\partial \Pi / \partial z)=0,(\partial \Pi / \partial w)=0,(\partial \Pi / \partial \eta)=0 ; \quad$ we have

$$
\begin{aligned}
& \frac{\partial \Pi}{\partial x}=0: x \sum_{i=1}^{8} \ln v_{c_{i}}^{2}+z \sum_{i=1}^{8} \ln v_{c_{i}} \ln v_{s_{i}}+w \sum_{i=1}^{8} \ln v_{c_{i}}=\sum_{i=1}^{8} \ln v_{c_{i}} \ln e_{m_{i}}, \\
& \frac{\partial \Pi}{\partial z}=0: x \sum_{i=1}^{8} \ln v_{c_{i}} \ln v_{s_{i}}+z \sum_{i=1}^{8} \ln v_{s_{i}}^{2}+w \sum_{i=1}^{8} \ln \rho_{i} \ln v_{s_{i}}+\eta \sum_{i=1}^{8} \ln v_{s_{i}}=\sum_{i=1}^{8} \ln v_{s_{i}} \ln e_{m_{i}}, \\
& \frac{\partial \Pi}{\partial w}=0: x \sum_{i=1}^{8} \ln v_{c_{i}} \ln \rho_{i}+z \sum_{i=1}^{8} \ln v_{s_{i}} \ln \rho_{i}+w \sum_{i=1}^{8} \ln \rho_{i}^{2}+\eta \sum_{i=1}^{8} \ln \rho_{i}=\sum_{i=1}^{8} \ln \rho_{i} \ln e_{m_{i}}, \\
& \frac{\partial \Pi}{\partial \eta}=0: x \sum_{i=1}^{8} \ln v_{c_{i}}+z \sum_{i=1}^{8} \ln v_{s_{i}}+w \sum_{i=1}^{8} \ln \rho_{i}+\eta \sum_{i=1}^{8} 1=\sum_{i=1}^{8} \ln e_{m_{i} .}
\end{aligned}
$$

Equations (5)-(8) can be converted into matrix equation for solution:

$$
\left.\begin{array}{cccc}
\sum_{i=1}^{8} \ln v_{c_{i}}^{2} & \sum_{i=1}^{8} \ln v_{c_{i}} \ln v_{s i} & \sum_{i=1}^{8} \ln \rho_{i} \ln v_{c_{i}} & \sum_{i=1}^{8} \ln v_{c_{i}} \\
\sum_{i=1}^{8} \ln v_{c_{i}} \ln v_{s_{i}} & \sum_{i=1}^{8} \ln v_{s_{i}}^{2} & \sum_{i=1}^{8} \ln \rho_{i} \ln v_{s_{i}} & \sum_{i=1}^{8} \ln v_{s i} \\
\sum_{i=1}^{8} \ln v_{c_{i}} \ln \rho_{i} & \sum_{i=1}^{8} \ln v_{s_{i}} \ln \rho_{i} & \sum_{i=1}^{9} \ln \rho_{i}^{2} & \sum_{i=1}^{9} \ln \rho_{i} \\
\sum_{i=1}^{9} \ln v_{c_{i}} & \sum_{i=1}^{9} \ln v_{s_{i}} & \sum_{i=1}^{9} \ln \rho_{i} & \sum_{i=1}^{9} 1
\end{array}\right]\left[\begin{array}{c}
\sum_{i=1}^{9} \ln v_{c_{i}} \ln e_{m_{i}} \\
z \\
w \\
\eta
\end{array}\right]=\left[\begin{array}{c}
9 \\
\sum_{i=1}^{9} \ln v_{s_{i}} \ln e_{m_{i}} \\
\sum_{i=1}^{9} \ln \rho_{i} \ln e_{m_{i}} \\
\sum_{i=1}^{9} \ln e_{m_{i}}
\end{array}\right] .
$$
$z, w$, and $C$ were solved through MATLAB software programming. Finally, the multiple regression model of $\mathrm{AE}$ energy $\widehat{e}_{m}$ was obtained as follows:

$$
\widehat{e}_{m}=170017.71 v_{c}^{0.3983} v_{s}^{-0.3129} \rho^{14.8305} .
$$

Similarly, the multiple regression model of the strength and stiffness of coal samples can be obtained as follows: where $\widehat{\sigma}_{b}$ and $\widehat{E}$ are the fitting values of the compression strength $\sigma_{b}$ and elastic modulus $E$, respectively.

Taking the loading rate of each specimen in the test, the acoustic velocity value of the coal sample, and the sample density into equations (10)-(12), respectively, the predicted AE energy value $\widehat{e}_{m}$, the predicted elastic modulus value $\widehat{E}$, 
TABle 5: Predicted values of $e_{m}, \sigma_{b}$, and $E$ of the coal sample.

\begin{tabular}{lccc}
\hline Sample number & $\widehat{e}_{m}\left(\mathrm{mv}^{*} \mathrm{~ms}\right)$ & $\widehat{\sigma}_{b}(\mathrm{MPa})$ & $\widehat{E}(\mathrm{GPa})$ \\
\hline M1 & 118957.07 & 16.59 & 1.44 \\
M2 & 134351.70 & 15.25 & 1.45 \\
M3 & 121526.90 & 9.21 & 0.83 \\
M4 & 146840.20 & 14.34 & 1.47 \\
M5 & 69322.43 & 12.78 & 1.62 \\
M6 & 394637.31 & 26.14 & 2.81 \\
M7 & 188630.53 & 11.87 & 1.29 \\
M8 & 730737.00 & 23.68 & 2.36 \\
\hline
\end{tabular}

and the predicted compressive strength value $\widehat{\sigma}_{b}$ can be calculated, and the detailed data are shown in Table 5.

In formula (10), there is a negative correlation between $\mathrm{AE}$ energy and sound velocity. Because the more pores in the coal sample, the lower the sound velocity, there are more pores in the coal sample with low sound velocity. During the coal sample loading process, the coal sample will have a larger AE energy during the process of pore compaction, so the measured $\mathrm{AE}$ energy value will also be larger.

In formula (11), there is a negative correlation between the coal sample strength and the loading rate. Because the peak strength of the coal sample increases first and then decreases with the increase of the loading rate, when the coal sample is loaded at a larger rate in the test, the strength of the coal sample will decrease as the loading rate increases. From the prediction model of coal sample strength, it can be obtained that the density factor has the greatest influence on the coal sample strength.

In formula (12), according to the parameters estimated by the parameters, it can be concluded that the density of the coal sample has the greatest influence on the elastic modulus, followed by the loading rate, and the sound velocity has the smallest influence.

Then the predicted value $\widehat{e}_{m}$ of AE energy was compared with the measured value $e_{m}$, and the correlation coefficient was calculated to analyze the rationality of the model. The corresponding correlation coefficient $R$ and significance level $P$ were obtained by MATLAB programming. The calculated values are as follows:

$$
\begin{aligned}
& R=0.93, \\
& P=0.0008 .
\end{aligned}
$$

Similarly, the predicted value $\widehat{\sigma}_{b}$ of compressive strength of coal sample is compared with the measured value $\sigma_{b}$ in order to calculate its correlation coefficient $R$ and significance level $P$ as follows:

$$
\begin{aligned}
& R=0.85, \\
& P=0.008 .
\end{aligned}
$$

The predicted value $\widehat{E}$ of the elastic modulus of coal sample was compared with the measured value; thus the

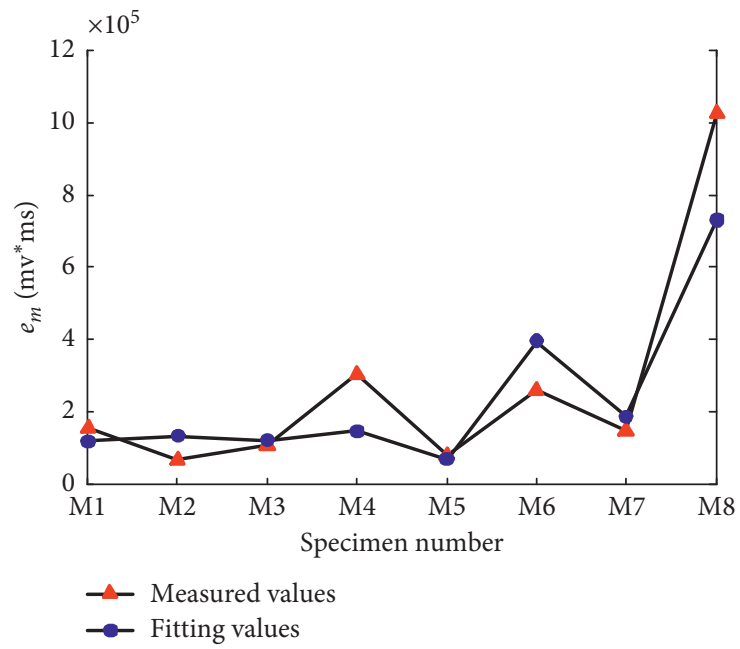

FIgURE 13: Comparison curve of measured value $\widehat{e}_{m}$ with fitted value $e_{m}$ of coal samples.

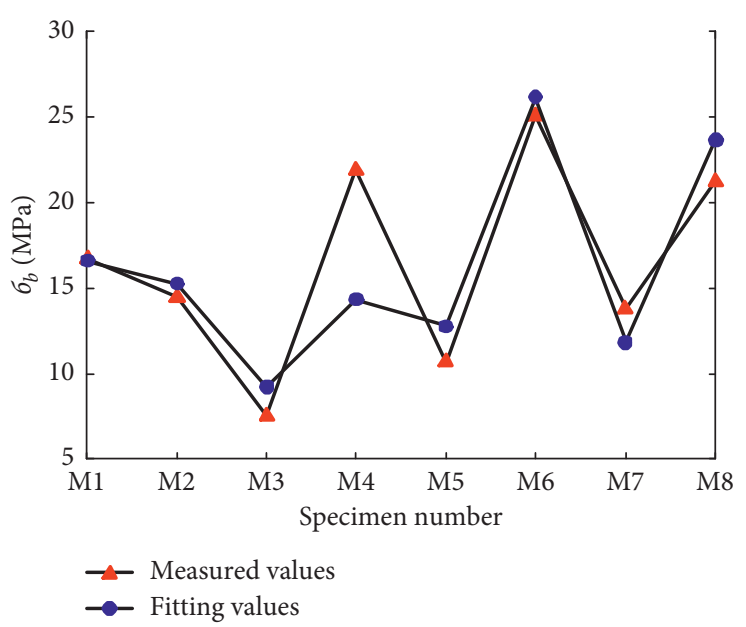

FIGURE 14: Strength comparison curves for measured values with fitted values of coal samples.

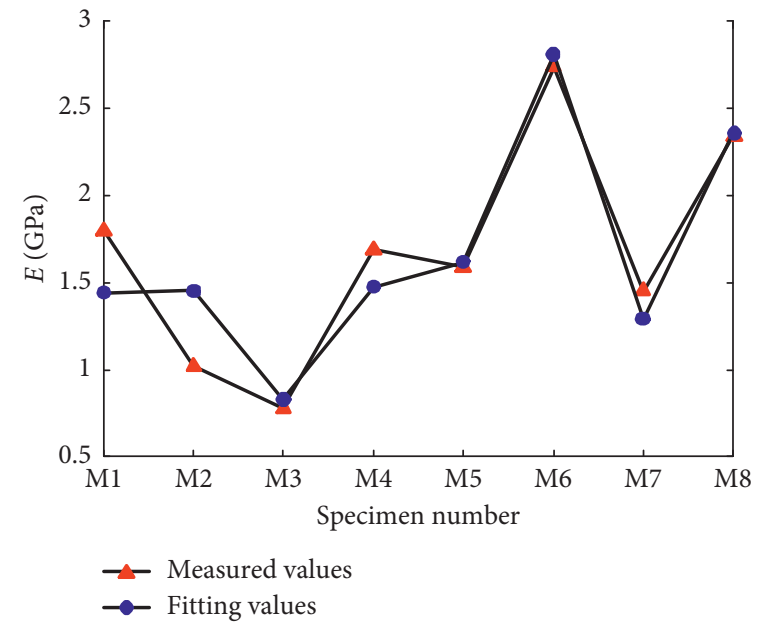

FIGURE 15: Elastic modulus comparison curves for measured values with fitted values of coal samples. 
correlation coefficient $R$ and significance level $P$ were calculated as follows:

$$
\begin{aligned}
& R=0.93, \\
& P=0.0008 .
\end{aligned}
$$

The comparison curves of the fitted values with the experimental values for uniaxial $\mathrm{AE}$ energy, compressive strength, and elastic modulus of coal samples are shown in Figures 13-15.

Because the correlation coefficient obtained is greater than or equal to 0.85 and the significance level is less than 0.05 , the multiple regression model established in this paper is reliable.

It can be seen that $\mathrm{AE}$ energy, uniaxial compressive strength, and stiffness of coal samples from the same geological source under a given loading rate can be better predicted by using the acoustic velocity in sample measured before the loading, mass density of coal samples, and the designed loading rate.

\section{Conclusion}

(1) In this paper, the effects of mass density, acoustic velocity, and loading rate on mechanical properties and $\mathrm{AE}$ characteristics of coal samples are considered comprehensively. The standard deviation and variation coefficient of density and acoustic velocity of coal samples are analyzed. The variation coefficient of the acoustic velocity in the coal sample is $49.56 \%$, which indicates that the mechanical properties of the coal sample are discrete.

(2) According to the test result, the AE energy of coal samples is less affected by the low loading rate. With the increase of loading rate, when the loading rate reaches a certain critical value, $\mathrm{AE}$ energy is higher than that of the other coal samples.

(3) Based on the principle of the least-square method, the multiple regression models of the maximum $\mathrm{AE}$ energy, compressive strength, and elastic modulus of coal samples were established, respectively, and the correlation coefficients were all greater than 0.85 . The results show that the $\mathrm{AE}$ energy, uniaxial compressive strength, and stiffness of coal samples from the same geological source can be predicted without repeated destructive tests by using the acoustic velocity measured before compression loading of coal sample, density, and loading rate.

\section{Data Availability}

The data used to support the findings of the study are included in the article.

\section{Conflicts of Interest}

The authors declare that they have no conflicts of interest.

\section{Acknowledgments}

The authors gratefully acknowledge the financial support from the National Natural Science Foundation of China (51574228 and 51674244), the Research Fund of the State Key Laboratory of Coal Resources and Safe Mining, CUMT (SKLCRSM19KF013), and the Fundamental Research Funds for the Central Universities (2020ZDPYZD02).

\section{References}

[1] C. Khazaei, J. Hazzard, and R. Chalaturnyk, "Damage quantification of intact rocks using acoustic emission energies recorded during uniaxial compression test and discrete element modeling," Computers and Geotechnics, vol. 67, pp. 94-102, 2015.

[2] C. Wang, X. Hou, Z. Liao, Z. Chen, and Z. Lu, "Experimental investigation of predicting coal failure using acoustic emission energy and load-unload response ratio theory," Journal of Applied Geophysics, vol. 161, pp. 76-83, 2019.

[3] V. Mlakar, F. P. Hassani, and M. Momayez, "Crack development and acoustic emission in potash rock," International Journal of Rock Mechanics and Mining Sciences \& Geomechanics Abstracts, vol. 30, no. 3, pp. 305-319, 1993.

[4] P. L. P. Wasantha, P. G. Ranjith, and S. S. Shao, "Energy monitoring and analysis during deformation of beddedsandstone: use of acoustic emission," Ultrasonics, vol. 54, no. 1, pp. 217-226, 2014.

[5] X. Chen, Z. Liao, and X. Peng, "Deformability characteristics of jointed rock masses under uniaxial compression," International Journal of Mining Science and Technology, vol. 22, no. 2, pp. 213-221, 2012.

[6] T. Liu, B. Lin, Q. Zou, C. Zhu, and F. Yan, "Mechanical behaviors and failure processes of precracked specimens under uniaxial compression: a perspective from microscopic displacement patterns," Tectonophysics, vol. 672-673, pp. 104-120, 2016.

[7] S.-Q. Yang, W.-L. Tian, Y.-H. Huang, Z.-G. Ma, L.-F. Fan, and Z.-J. Wu, "Experimental and discrete element modeling on cracking behavior of sandstone containing a single oval flaw under uniaxial compression," Engineering Fracture Mechanics, vol. 194, pp. 154-174, 2018.

[8] K.-D. Liu, Q. S. Liu, Y. G. Zhu, and B. Liu, "Experimental study of coal considering directivity effect of bedding plane under Brazilian splitting and uniaxial compression," Chinese Journal of Rock Mechanics and Engineering, vol. 32, no. 2, pp. 308-316, 2013.

[9] Y. L. Yan, T. Xu, S. Y. Ren et al., "Study on the influence of joints occurrence on uniaxial compressive strength of rock," Chinese Journal of Underground Space and Engineering, vol. 12, no. 4, pp. 897-903, 2016.

[10] P. Hou, F. Gao, Y. G. Yang et al., "Effect of bedding plane direction on acoustic emission characteristics of shale in Brazilian tests," Rock and Soil Mechanics, vol. 37, no. 6, pp. 1603-1612, 2016.

[11] Z. H. Lin, W. Xiang, and Y. M. Zhang, "Experimental research on influences of physical indices and microstructure parameters on strength properties of red stone from western Hunan," Chinese Journal of Rock Mechanics and Engineering, vol. 29, no. 1, pp. 124-133, 2010.

[12] Y. S. Tang, H. L. Yao, Y. Liao et al., "Study on the influences of weak interlayer inclination on physical mechanics properties of coal bearing sandstone," Mining Research and Development, vol. 38, no. 08, pp. 51-55, 2018. 
[13] Y. Q. Song, M. Li, J. Liu et al., "Experiment test on marble containing natural weak interlayer of different angles," Journal of China University of Mining \& Technology, vol. 44, no. 4, pp. 623-629, 2015.

[14] X. Kong, E. Wang, X. He, E. Zhao, and C. Zhao, "Mechanical characteristics and dynamic damage evolution mechanism of coal samples in compressive loading experiments," Engineering Fracture Mechanics, vol. 210, pp. 160-169, 2018.

[15] Y. Wang, J. Tang, Z. Dai, and T. Yi, "Experimental study on mechanical properties and failure modes of low-strength rock samples containing different fissures under uniaxial compression," Engineering Fracture Mechanics, vol. 197, pp. 1-20, 2018.

[16] C. A. Tang, L. G. Tham, S. H. Wang, H. Liu, and W. H. Li, "A numerical study of the influence of heterogeneity on the strength characterization of rock under uniaxial tension," Mechanics of Materials, vol. 39, no. 4, pp. 326-339, 2007.

[17] H. H. Song, Y. X. Zhao, Y. D. Jiang, and X. Zhang, "Influence of heterogeneity on the failure characteristics of coal under uniaxial compression condition," Journal of China Coal Society, vol. 42, no. 12, pp. 3125-3132, 2017.

[18] S. Y. Wang, S. W. Sloan, D. C. Sheng, and C. A. Tang, “3D numerical analysis of crack propagation of heterogeneous notched rock under uniaxial tension," Tectonophysics, vol. 677-678, pp. 45-67, 2016.

[19] J. Liu, D. Liu, Y. Cai, Q. Gan, and Y. Yao, "Effects of water saturation on P-wave propagation in fractured coals: an experimental perspective," Journal of Applied Geophysics, vol. 144, pp. 94-103, 2017.

[20] A. Jamshidi, M. R. Nikudel, M. Khamehchiyan, and R. Z. Sahamieh, "The effect of specimen diameter size on uniaxial compressive strength, $\mathrm{P}$-wave velocity and the correlation between them," Geomechanics and Geoengineering, vol. 11, no. 1, pp. 13-19, 2016.

[21] A. A. Shahri, S. Larsson, and F. Johansson, "Updated relations for the uniaxial compressive strength of marlstones based on P-wave velocity and point load index test," Innovative Infrastructure Solutions, vol. 1, no. 1, pp. 1-7, 2016.

[22] D. J. Armaghani, E. T. Mohamad, M. Hajihassani, S. Yagiz, and H. Motaghedi, "Application of several non-linear prediction tools for estimating uniaxial compressive strength of granitic rocks and comparison of their performances," Engineering with Computers, vol. 32, no. 2, pp. 189-206, 2016.

[23] S. Dehghan, G. Sattari, S. Chehreh Chelgani, and M. Aliabadi, "Prediction of uniaxial compressive strength and modulus of elasticity for Travertine samples using regression and artificial neural networks," Mining Science and Technology (China), vol. 20, no. 1, pp. 41-46, 2010.

[24] S. S. Matin, L. Farahzadi, S. Makaremi, S. Chehreh Chelgani, and G. H. Sattari, "Variable selection and prediction of uniaxial compressive strength and modulus of elasticity by random forest," Applied Soft Computing, vol. 70, pp. 980-987, 2017.

[25] M. Khandelwal and T. N. Singh, "Correlating static properties of coal measures rocks with P-wave velocity," International Journal of Coal Geology, vol. 79, no. 1-2, pp. 55-60, 2009.

[26] H. Jia, E. Wang, D. Song, X. Wang, and M. Ali, "Precursory changes in wave velocity for coal and rock samples under cyclic loading," Results in Physics, vol. 12, pp. 432-434, 2019.

[27] H. T. Li, C. X. Jiang, Y. D. Jiang et al., "Mechanical behavior and mechanism analysis of coal samples based on loading rate effect," Journal of China University of Mining and Technology, vol. 44, no. 3, pp. 430-436, 2015.
[28] B. Huang and J. Liu, "The effect of loading rate on the behavior of samples composed of coal and rock," International Journal of Rock Mechanics and Mining Sciences, vol. 61, pp. 23-30, 2013.

[29] Y. W. Li, Y. D. Jiang, Y. M. Yang et al., "Research on loading rate effect of uniaxial compressive strength of coal," Journal of Mining and Safety Engineering, vol. 33, no. 4, pp. 754-760, 2016.

[30] D. J. Xue, H. W. Zhou, Z. H. Wang, W.-G. Ren, M. Zhang, and Y.-Q. Liu, "Failure mechanism and mining-induced mechanical properties of coal under different loading rates," Journal of China Coal Society, vol. 41, no. 3, pp. 595-602, 2016.

[31] L. Zhou, Z. Zhu, H. Qiu, X. Zhang, and L. Lang, "Study of the effect of loading rates on crack propagation velocity and rock fracture toughness using cracked tunnel specimens," International Journal of Rock Mechanics and Mining Sciences, vol. 112, pp. 25-34, 2018.

[32] J. Wang, Z. Wang, and S. Yang, "A coupled macro- and mesomechanical model for heterogeneous coal," International Journal of Rock Mechanics and Mining Sciences, vol. 94, pp. 64-81, 2017.

[33] L. G. Qi, K. Yang, W. Lu et al., "Statistical analysis on uniaxial compressive strength of coal measures," Coal Science and Technology, vol. 41, no. 2, pp. 100-103, 2013.

[34] C. H. Zhang, Q. S. Zhao, and Y. J. Yu, "Probability model of heterogeneous coal considering correlation of mechanical parameters," Rock and Soil Mechanics, vol. 32, no. 2, pp. 564-622, 2011. 